\title{
CURRICULUM DEVELOPMENT THROUGH CRITICAL COLLABORATIVE PROFESSIONAL ENQUIRY
}

\author{
Valerie Drew, Mark Priestley, Maureen K. Michael \\ School of Education, University of Stirling
}

\section{Background}

In recent years, we have witnessed changing fashions in curriculum policy (Priestley and Biesta 2013) in many countries. A particular trend is an apparent reinstatement of the teacher as an active agent of change in developing the curriculum, seen in a shift from input regulation of the curriculum to output regulation (Kuiper and Berkvens 2013). The former is about tight front-door prescription of the curriculum (ibid.), typically with mandated content, and in some cases regulated pedagogy. The latter is back-door regulation of the outcomes of teaching, for example through inspections and the evaluative use of examinations data. Ostensibly, this might seem to afford teachers greater autonomy in curriculum making. Underpinning such trends has been an ongoing debate about the success or otherwise of mandated curriculum reform policy (e.g. Cuban 1998). A specific concern has been the 'implementation gap' (Supovitz and Weinbaum 2008) between policy intention and classroom practice, attributed to the potential for teachers to significantly modify or mediate the intrinsic logics of the curriculum policy to match the institutional logics of the setting where it is enacted (Young 1998), even where input regulation has been tightly prescribed as in the case of England's 1988 National Curriculum (Bowe et al. 1992).

The evolution of curriculum policy in recent years recognises, at least in part, that there needs to be more nuanced ways of framing the role of teachers in curriculum making. Scotland's Curriculum for Excellence (CfE), for example, strongly emphasises the key role of teachers in shaping curricular practices:

In the past, national curriculum developments have often been supported by central guidelines, cascade models of staff development and the provision of resources to support the implementation of guidance by teachers. Our approach to change is different. It aims to engage teachers in thinking from first principles about their educational aims and values and their classroom practice. The process is based upon evidence of how change can be brought about successfully - through a climate in which reflective practitioners share and develop ideas. (Scottish Executive 2006, p. 4)

Combined with this curricular shift has been the development of a wider transnational discourse that 'teachers matter' (OECD 2005), characterised by talk of lifelong professional learning, teaching as a Master's level profession, teacher autonomy and teachers as agents of change. Again, Scotland's policy landscape manifests similar trends; the influential report Teaching Scotland's Future (TSF) (Donaldson 2010) is currently shaping approaches to educational leadership and teacher professional learning. This report advocates the development of new forms of 'partnership working' between universities, schools and local authorities to foster the implementation of CfE. The TSF report espouses particular ways of thinking about career-long professional learning which seeks to promote an understanding of teachers as 'reflective and enquiring teachers who are engaged in continuous improvement' (p.15) and 'have the capacity to engage fully with the complexities of education and to be key actors in shaping and leading educational change' (p. 19). 
While this potential transformation of the professional role of teachers has been welcomed in many quarters, such developments may also be highly problematic. Although the shift from input regulation has been accompanied by a rhetoric of teacher autonomy, output regulation has arguably eroded such autonomy (Biesta 2004), through encouraging the development of highly performative cultures in schools (for example see: Jeffrey and Troman 2013). Thus effectively 'giving with one hand and taking away with the other' (Leat 2014, p. 69). Moreover, the siren call for greater teacher autonomy conflates the related concepts of teacher autonomy and teacher agency. We would argue that the former - as it is frequently misunderstood in colloquial discourse (i.e. as a comparative lack of regulation of teachers' work) - is an insufficient condition for teacher professional action. Autonomy may foster 'going with the flow' and reproduction of habitual patterns of behaviour, rather than constructive professional engagement with educational change agendas. Agency, on the other hand, might be said to be dependent not only on high teacher capacity, but crucially on the availability of resources - cultural, relational and material - that facilitate effective practice (for a detailed discussion of an ecological view of teacher agency, see: Priestley et al. 2015). Such resources might include constructive collegial and external support for innovation, conceptual framings for educational practice, research findings and intelligently framed educational policy (i.e. curriculum regulation). Furthermore teacher mediation of policy has often been framed in negative or even pejorative ways, driven by notions that enacted practice should have fidelity with the intentions espoused in curriculum policy (Cuban 1998). The concept that teachers matter has tended to lead to an overemphasis on the importance of individual teacher capacity and a neglect of the structural, relational and cultural conditions that frame teaching, and which make effective teaching possible (see Priestley et al. 2015).

In this policy context, there has been a resurgence of interest in the methodology of [collaborative] professional enquiry (and similarly termed processes such as practitioner enquiry/inquiry or research), most of which have their origins in action research (also see: General Teaching Council for Scotland 2012, Education Scotland 2013), as part of a wider movement towards the development of teacher professional learning communities (PLCS) (for example, see: Cochran-Smith and Lytle 2009; Stoll et al. 2006; Vescio et al. 2008). According to Butler and colleagues (2015, p. 2), such 'inquiry-based approaches, [...] have potential to impact not only teachers' learning but also their practice in classrooms', thus offering a promising alternative to top-down dissemination and narrow implementation of educational policy. These authors point to the potential for such approaches to actively engage teachers, encourage risk-taking and foster persistence as teachers work through innovation. Moreover, because they engage teachers systematically with innovation, they have the potential to address an oft-cited criticism of the PLC, namely that their architects can tend to neglect attention to the nature and quality of connections between actors within the community (Coburn and Russell 2008). Thus, [collaborative] professional enquiry is now widely seen as a powerful means of fostering both teacher professional learning and innovation ${ }^{1}$. It is viewed as a means of engaging members of the education community to work in partnership to explore aspects of mutual interest or concern with 'the ultimate aim of improving educational outcomes for students' (DeLuca et al. 2015, p.640). However, while many of those engaged in developing professional learning strategies for teachers may welcome the policy makers' endorsement of this type of professional engagement, there is a need to exercise caution, since utilising such approaches as a vehicle for policy implementation and teacher improvement may be considered to be in tension with the philosophy of this methodology, which is to ask 
critical questions of the impact of policies and practices on professional work and those they work for (for example, see: McNiff and Whitehead 2010; Kemmis 2006; Jones and Stanley 2010).

This paper reports upon a curriculum development project that has been developed, in the light of the abovementioned trends and concerns, by the School of Education at the University of Stirling in collaboration with a Scottish Local Education Authority. The project is underpinned by a systematic methodology termed Critical Collaborative Professional Enquiry (CCPE), informed by previous research (for example see: Drew 2013; Reeves and Drew 2012, 2013; Fox 2009; Reeves and Fox 2008) and the experiences of leading Master's level programmes in professional education. CCPE takes cognisance of a number of issues raised elsewhere in the literature about perceived limitations or concerns with practitioner research. In this paper, we first provide a brief overview of these concerns, before outlining the project, the research undertaken in tandem with it and the empirical findings in relation to effective and sustained curriculum innovation in schools.

\section{Professional enquiry: a critique - some themes from the literature}

A fundamental tension in professional enquiry relates to the purpose for which it is undertaken. An enquiry methodology can start with consideration of educational purposes, principles and values, which then permeate the processes subsequently undertaken; or alternatively, enquiry can be reduced to more instrumental and/or short-term concerns, for example serving as a narrow mechanism for implementing policy or developing new technical approaches (Somekh and Zeichner 2009; Kemmis 2006). Key questions relate to whether professional enquiry is mindful of social justice (Griffiths 2009) and how it will 'take into account ethical, political and moral concerns' (Klein 2012, p. 8). This is fundamentally about asking critical questions that matter. This issue links to a number of practical concerns. First, there is the question of whether professional enquiry can interrupt current, habitual and often deep-grained practices and ways of seeing the world of schooling, or whether such processes simply provide a mechanism for reinforcing existing ways of thinking, through the reinforcement of dominant, mono-cultural discourses.

Second, and linked to this, are issues of power and control. Put simply, one might pose the question 'whose enquiry?' Recent research suggests that successful innovation needs to create a culture of enquiry that respects the voices of teachers and their professional knowledge (e.g. Zeichner 2002). Professional enquiry can be undermined by authoritarian leadership reflecting a different world view to that of the teachers undertaking the enquiry, exposing tensions between the bottom-up elements of professional enquiry and top-down, often externally driven school improvement agendas. It may also be weakened in situations where teachers find that their colleagues either do not share their zeal for the enquiry, or feel threatened by it. As above, genuine innovation is not fostered by disingenuous attempts to use professional enquiry as a control mechanism to narrowly implement mandated policy (Somekh and Zeichner 2009); instead, a culture of enquiry needs to attend to school micro-politics, and to question the notion of leadership as only hierarchical.

Third, a number of authors (see for example DeLuca et al. 2015; Meirink et al. 2010; Zeichner 2002) have pointed to the practical constraints on professional enquiry resulting from limitations in space and time. Professional enquiry requires space for dialogical working, and a sustained period for engagement. This is essential if teachers are required to make sense of new and complex ideas, engage with research findings, 
change their emotional and cognitive attachments to former patterns of thinking and practice and enact and evaluate new ways of doing. Thus, Deluca and colleagues (2015) emphasise the need to protect sanctioned time; Zeichner (2002) has highlighted the need for collaboration over a substantial period - at least a year during which teachers are able to collaborate in a safe and supported environment; and Meirink and colleagues (2010) have stressed the particular importance of an extended period of engagement during the initial stages of an enquiry to enable teachers to make sense of and align goals.

A further practical issue relates to the knowledge and skills possessed by teachers undertaking professional enquiry. In particular, this applies to skills of data collection and analysis (Zeichner 2002). Teachers are not professional researchers, and may lack the requisite skills, including an ability to determine what counts as baseline evidence, or evidence of a successful enquiry (DeLuca et al. 2015). Finally, while such weaknesses can be mitigated by the provision of external support, for example from university researchers or coaches (Coburn and Russell 2008), sustainability remains as a major issue. I'Anson et al. (2008) also suggest and that in order to become sustainable, enquiry must become 'an orientation to practice, a professional disposition' (p.73); a view shared by Cochran-Smith and Lytle (2009). A number of authors report on the vulnerability of working practices associated with professional enquiry to various threats such as lack of a supportive culture and relations (for example see: Reeves and Drew 2013). This links to the thorny question of what happens once a supported project comes to a close, and the school is left to work alone. The literature on educational change is replete with examples of projects that have thrived during the introductory phase, before quickly fading away once support was withdrawn (e.g. McNiff and Whitehead 2011; Giacquinta 1998). Kemmis (2009) suggests that AR supports sustainable changes in practice through transforming 'practitioners' practices, their understandings of their practices and the conditions in which they practice' (emph. in original). However this requires a form of educational leadership that fosters and sustains these educational practices through paying attention to how leadership, teaching, professional and student learning, research and reflection on practices are understood and practiced in educational settings (Wilkinson and Kemmis 2014) through democratic ways of working.

\section{Critical Collaborative Professional Enquiry}

The School-based Curriculum Development through Critical Collaborative Professional Enquiry project has run with yearly cohorts of around 25 teachers since 2012. The project originated through dialogue between Local Authority Education Officers and University researchers/tutors about how they might work in partnership to address some of these complex and intertwining issues discussed above and arising from the policy imperative to build 'the collective capacity of practitioners to learn, innovate and evaluate in effective ways so that a vibrant culture of collaborative learning and enquiry becomes a powerful driver of improvement in every sector' (Education Scotland 2013). Throughout the project, there has been a strong focus on ensuring that values and beliefs pertaining to issues of social justice are surfaced, examined and challenged through 'asking critical questions of policies and practices' (General Teaching Council for Scotland 2012). Each cohort comprised small groups of teachers (typically four to six) from early years, primary and secondary schools in the authority, attending six workshops over an academic session (approximately nine months). From the outset, there was an expectation that each school should send a group of teachers, including at least one member of the senior leadership and management team. 
There are multiple frameworks and/or models for similar methodologies of enquiry or action research (for example see: Coghlan and Brannick 2014, McNiff 2013, McNiff and Whitehead 2011, Koshy, 2010) and authors tend to agree that there is no single or correct way of implementing this methodology. In a review of 42 studies of collaborative inquiry DeLuca et al. (2015) identified between three and eleven steps or stages in the models and frameworks examined, but within these recognised three principal interrelated structural elements, namely, dialogic processes, taking action and engaging in reflection; these elements are embedded in the CCPE model. The School-based Curriculum Development through Critical Collaborative Professional Enquiry project was a Master's level professional learning programme comprising a two stage process:

- Stage 1: a conceptual phase which involved engaging with the 'big ideas' of the curriculum², considering fitness for purpose of pedagogies and addressing contextual conditions.

- Stage 2: undertaking Critical Collaborative Professional Enquiry (CPE), a methodology, derived from action research, comprising three phases: focusing, interrupting and sense making (adapted from Drew et al. 2008) to trial new ways of developing school-based curriculum development with an impact on outcomes for teachers and their students.

The aim of the first stage is to engage practitioners with the principles and purposes of current curricular policy in Scotland, addressing the issue, highlighted by research, that many teachers have a poor understanding of these (Priestley and Minty 2013). The emphasis at this stage is not on change per se, but on critical engagement, with the aim of developing 'good' educational practices from the conceptual framing provided by the new curriculum. Underpinning this activity is an assumption that existing practices might be fit-for-purpose, but that participants do not necessarily know whether this is the case unless they are critically evaluated against the benchmarks provided by the CfE attributes and capabilities as well as broader educational purposes, principles and values; conversely, such an evaluation might lead to significant change in practices. This involves an exploration of: the principles and purposes or 'big ideas' of the curriculum, fitfor-purpose knowledge/content (something that has been comparatively neglected in CfE; e.g. see: Priestley and Minty 2013), and the framing of appropriate practices through fit-for-purpose pedagogies. Participants are encouraged to think about barriers and drivers to their planned innovation, stimulating discussion about how, for example, accountability practices and school systems might impede their plans. At this stage, the value of the participation of senior school managers, both as participants and as critical colleagues, is clearly evident, with less likelihood of participants being subsequently blocked in taking forward their planned innovations, if senior managements had been involved in the process.

The conceptual stage described above ensures that professional enquiry is rooted in educational purpose. The CCPE stage involved three phases: focusing, interrupting and sense-making. During the first phase, the participants engage in professional dialogue about school-based curriculum development to identify an area of interest or concern in their practice related to pedagogy, content or assessment. Throughout this stage the participants develop the focus of the enquiry through engaging critically with ideas in research and academic readings, as they begin to form the enquiry question that will guide their innovation, and as they attend to principles of social justice and sustainability of practices, underpinned by their codes of professional ethics. By the end of this phase the CCPE group generate and agree a broad 'critical' question 
for their enquiry and devise a collaborative plan for implementing the critical enquiry through interrupting practice. In Phase Two of CCPE, groups interrupt existing practices through implementing and trialling new approaches. They continue to critique and refine or modify their conceptual framework during this phase, through ongoing critical engagement with reading and professional dialogue, both within the CCPE group and with other members of the educational community including the University researchers and colleagues. The process of engaging in systematic generation and gathering of empirical data (both process and outcomes) takes place throughout all three stages but is perhaps most prevalent during this stage as the practitioners implement the interruption in practices, and begin to notice changes in their knowledge, understanding and practices, as well as the impact on their students' learning experiences. In Phase Three there is a focus on collaborative sense-making through critical analysis of data and interpretation of evidence, as the CCPE group begin to evaluate the impact of the interruption and draft a 'report' for dissemination to their educational community. However, this sense-making process permeates all three phases, as participants invoke professional judgement to make sense of the data generated throughout the enquiry and use this to evidence their claims and assertions about the contribution of the process to: developing pupils' attributes and capabilities; enhancing their professional learning in relation to development of educational practices; and identifying messages for the wider school community.

\section{Research design}

The research was guided by the following research questions:

1. How did the project impact on educators' knowledge, understandings and practices in their settings?

2. In what ways did the project shape the agency achieved by teachers in their professional work?

3. In what ways did the project facilitate school-based curriculum development and affect practices in the participating schools?

A rich variety of qualitative data was generated from the project. These included data generated by activities associated with the project, as well as follow-up research. Data included:

- Formal semi-structured telephone interviews with 6 participants, including school leaders.

- Programme evaluation questionnaires.

- Field notes from participant observation in project workshops

- Artefacts generated by cohorts through various pedagogical activities

- Mid/end of programme feedback from participants

- Artefacts generated for group presentations.

Drawing in this way from multiple data sources allowed the research team to construct a rich picture of the context being researched. Interview data and other written transcripts (for example field notes) were coded following an interpretivist approach (Corbin and Holt 2005), which allowed for both a process of open coding of data and the subsequent application of theoretical framings (for example curriculum theory (principles and practices), the ecological approach to teacher agency (Priestley et al. 2015), professional learning and practices). 
The research complied with the ethical guidelines of the British Educational Research Association, and ethical clearance was obtained from the Research Ethics Committee of the School of Education at the University of Stirling. While it is not possible to guarantee full anonymity in a publicly-run project of this nature, we have sought to minimise the risk of identification by referring to participants by role only (e.g. EYCT = early years classroom teacher, $\mathrm{PHT}=$ primary head teacher, $\mathrm{SDHT}=$ secondary deputy head teacher, $\mathrm{SCT}=$ secondary classroom teacher, etc.). Schools are only identified by sector (primary/secondary). All participants are referred to as female, in order to further minimise risk of identification.

\section{Outcomes}

We found that involvement in this programme exerted a powerful effect on the teachers who participated. In turn this opened up new ways of working in school with the potential for enhanced practice and outcomes for children. In the sections which follow, we identify some of these effects, with reference to the data from the study.

\section{CCPE as a stimulus to new ways of thinking}

We found significant evidence of enhanced understandings of $\mathrm{CfE}$, addressing one of the major concerns that had originally stimulated the programme development. In a sense this is not surprising; previous research (Priestley and Minty 2013) had already suggested that schools did not provide adequate spaces for sense-making when the curriculum was first introduced, and the programme established such spaces, through the setting up of structured dialogue. A number of participants articulated renewed engagement with and deeper understandings of the core aims/principles and purposes of the curriculum. This phenomenon was variously described as 'refocusing' [SDHT2] or 'going back to what CfE was meant to be about - to the big ideas, the four capacities' [SCT6], 'a broader sense of CfE and all the possibilities that are in there...' [SDHT2]. One participant described this as 'a bit of an a-ha moment, a bit of a revelation' which gave access to the bigger picture, and helped her 'to really look at curriculum from design principles, the origins of the curriculum, rather than the $\mathrm{Es}$ and $\mathrm{Os}^{3}$ which were an interpretation of the basic fundamental principles' [PHT1]. It is significant that participation in the project also led to enhanced understandings in relation to related and relevant concepts such as metacognition. This appears to be a consequence of the sustained professional reading associated with the innovations undertaken by each school:

Read stuff I had never heard of before ...from Canada, from America it really helped me have a wider perspective about had been done in other places... what had worked what didn't work, what had been taken forward and so how it could be taken forward in [our setting]. [SDHT1]

The research also suggests that participants developed better understanding of the potential links between these purposes and their resulting practices. For instance, some participants realised that they had been conflating the two, often treating particular methods of educating (such as active learning methodologies) as ends in themselves, rather than as means of addressing broader educational aims. A greater understanding of the links between the purposes and practices of the curriculum was accompanied by enhanced understanding of curriculum development processes. Participants described how the project had opened up new possibilities in these practices, expanding their repertoire for manoeuvre (Priestley et al. 
2015) as they developed CfE. The opportunity to design curriculum from an alternative starting point was considered 'refreshing' by one participant; she did not feel so 'bogged down with specific details of curriculum, of specific attainment pointers, not focusing on specific strategies or programmes', relishing the lack of 'prescription' in the programme which offered 'a bit more freedom' than usual [PHT1]. Other participants welcomed the way the project 'allowed practitioners to be creative and innovative' [PHT2] and 'made you think anything is possible' [SDHT2]. Enhanced understandings in turn led to a number of schools reporting changes to planning processes. For example one school reconfigured their approach to planning 'to begin with the Four Capacities, whereas previously it had started with the Experiences and Outcomes' [PHT1]. Another school revised the planning process, starting 'by engaging in professional dialogue across the year groups/age groups, allowing teachers to adapt their practices using different approaches for each level' [PHT2]. A third school reported that their planning 'is now much more child centred, child led and responsive'.

The enhanced understandings discussed above appear to have fostered the development of criticality - a more constructive critical engagement with practice - through engagement with academic literature and research, and working with external partners. The reflections of one head teacher neatly illustrate this tendency, which was evident throughout the data:

I knew that that was exactly what we needed as a staff, that we needed externality because I have been there 4 years now but a lot of staff have been there a really long time and we just did things the way we did things, It has raised the level of thinking in the establishment. [PHT1]

She expanded on this point as follows:

[the tutor] was able to give us access to good quality reading around the areas of pedagogy that we were interested in, so that was one of the really good things for me - but then also to have the discussion with colleagues over articles that we had read, sharing thoughts, ideas and being critical of ideas. That was just tremendous and it was really great to be doing that with my staff, rather than with a head teacher group. [...] Without that, people just talk like they're technicians, they just talk about the job like it's a manual, like this is what this reading scheme says; there's not a level of thinking, critical thinking, thinking outwith your own experience without that, so people just go over the same old arguments they've always gone over before, they say the same things that they've said for years. [PHT1]

\section{CCPE as a stimulus to new ways of working}

As we have noted, continuing professional development has tended to focus on changing the teacher improving their capacity, knowledge, skills, et cetera - rather than addressing cultural and structural issues with shape ensuing practices. Our data suggest that teachers' participation in CCPE has exerted some effect on the latter two dimensions of professional working. There is evidence of impact on school culture in the schools, for example increased concern for social justice in educational practice, and increasing desire and ability to justify such practice in terms of values and principles. As we have emphasised, the pedagogies of the programme were planned to surface issues of social justice and these were variously taken up by 
different groups. For instance, one teacher suggested that the process 'makes you think more broadly about what is going on for young people across Scotland' [SDHT2]; there was discussion about helping to develop pupils' voice and ownership of their learning, and enabling schools to make the curriculum process 'work for our children and our community' [PHT1].

The programme was deliberately set up to establish collective networking and to interrupt existing hierarchies, both in and out of participants' work settings. Many comments related to how the process had both relational and professional impact. For example one participant declared that 'the impact of the CCPE on relationships with colleagues was brilliant - we really enjoyed working together it made a lot of sense' [SCT5], an important factor if groups are to achieve their goals. Although the primary reason for requiring each of the schools to include a member of the senior management team in their group was to ensure that the enquiries were allocated adequate time, space and support in the school settings, there were additional tangible effects on school cultures and on power dynamics in what has been a traditionally hierarchical profession in Scotland, where there are long chains of command from central government through local education authorities and school senior management teams, and where classroom teachers did not even have a formal responsibility for curriculum development until comparatively recently (Boyd and Norris 2006). Of particular note was an apparent flattening of hierarchies. A number of interviewees held senior management roles, and their comments reveal their perceptions of the value of collaborative and collective working in both developing criticality and disrupting power relations.

[The enquiry] brought us together as critical thinkers in a way that we hadn't been before... and I might be wrong, I might be kidding myself on, but I think it kind of flattens the hierarchy a bit. I think it gave people confidence in having an equal say in the discussion, shared the power a bit. [PHT1].

I was to show my commitment to my staff as well - it wasn't my plan, my question - round that table I was an equal with them. [PHT2]

We ended up much more as a group and I was genuinely working as one of them... going through processing and planning together, good fun as well as work. [SDHT2]

One of the deputy head teachers also hinted at the development of criticality in suggesting that whilst this was 'in some ways quite an academic approach... it really works for school improvement because you are working collegiately with staff who are actually going to be involved in delivering the changes and measuring the impact...'. She highlighted the collaborative nature of the methodology as one of the most positive aspects of the programme stating that 'it's a good way of getting team together, because you're working together, you're sharing your research, sharing your understanding, you're looking at the success' [PDHT2].

In the light of the above, it is not surprising that some participants reported quite radical changes to pedagogical practices, particularly in relation to interdisciplinary learning. Enhanced understanding of 'how an interdisciplinary learning project cuts across all four capacities of CfE and how learning goes beyond subject boundaries' alongside the benefits for young people in making connections between different areas of their learning' [SCT5] was reported by one secondary teacher. In another case, the emergence of 'one teacher at each stage in the school thinking about what would be powerful knowledge for their class and 
negotiating that with their class' had translated into 'immediately changing the way a group of staff worked, particularly in terms of interdisciplinary learning' [PHT1]. Another teacher related that 'we are looking at altering our planning... involving children more in the learning and teaching cycle and looking at skills as well as knowledge in wider areas of the curriculum' [EYCT1]. Some of these changes were reported as having direct impact on pupils' learning and experiences: in one of the secondary schools an insight that 'resilience ties in with the philosophy of CfE' prompted teachers to think about how 'to develop skills first so pupils can access the curriculum' [SDHT2]; and a primary head teacher noted that learners 'are much more interested and excited and motivated by the much more child centred learning' [PHT1].

The above discussion suggests that CCPE has acted as a stimulus for change -in some cases radical - to teachers' practices. However, as we noted in our review of the literature, this does not address the issue of sustainability. The question of the sustainability of projects, once external provocation and support is withdrawn is an issue highlighted by a number of authors (for example see: Reeves and Drew 2013; de Luca et al. 2015). Indeed, a number of participants alluded to the challenges of engaging in or committing to systematic CCPE methodology after withdrawal of the external support for this particular project. One participant declared that 'our 'team' is trying to keep it going, but I don't know what kind of form it's going to take' and also noted that although 'they have introduced professional enquiry groups in school it has not been given the chance, the timings were all wrong...' [SCT6]. Others noted similar concerns:

I am worried that not having the enquiry [project] there, that we stop the process... it gave us an opportunity to get stuck into the process and do something that really mattered... and the momentum may get lost as we get sucked back into the daily grind. [SDHT2]

The project is now entering its fourth year, and while it is too early to make strong claims about sustainability, nevertheless a number of participants reported sustainable impact on practices in their schools as a result of engaging on the programme. An emerging trend is the continued use of variants of the CCPE approach to develop the curriculum and foster innovation in a number of schools. In one school (a participant in an early cohort), the head teacher and staff have developed a continued programme around collaborative professional enquiry that has persisted since the end of her engagement in the project, and which is claimed to be fostering continued innovation.

The second thing is that we've now adopted collaborative professional enquiry as a, probably as our biggest mode of professional learning within the school. So we had 8 on the original enquiry, there were 10 on the next enquiry this year, next year we're going to have 2 enquiries going on so that, I think before when people were looking at their professional development they were looking at what courses they could go on but now people are saying what can we be enquiring about this time and what is relevant [PHT1].

Another of the participating primary schools now uses the model to support their probationer teachers who are required to undertake a 'mini enquiry' [PDHT2; PHT2]. In this school, the model has been extended to encourage colleagues to engage with research. 
Because this programme demonstrated the impact of collaborative professional learning one of the things we are taking from it is that we are doing professional reading groups in the school - not to the same extent as the CPE - but if we are planning to do anything in school - how can we read about it before hand - how can we question what is there - how could we then potentially implement that in our school - but we are really lucky as we have now had three groups go through the CCPE programme - so I now have a bulk of staff who know that it means more than just reading a book... [PHT2]

Other participants continue to use the model to develop their practice. For example, one secondary teacher has since used the model for her own enquiries 'to establish whether it has an impact; and it has made me do some academic reading around the topic' [SCT5]. These claims point to changes in what people are doing, in their understandings and in the conditions for their practice linked to adopting elements of the CCPE methodology. Thus in deliberately attending to both the how and what of practice, the CCPE model appears to create possibilities for developing the 'coherent patterns' of practice which are required for sustainable and transformational change (Kemmis 2009). Furthermore, these examples provide evidence of sustainability in professional learning and practice as practitioners adopt a view of professional learning as an emergent process where CCPE supports them in 'theorising of practice in context' (McAteer 2013).

\section{CCPE and teacher agency}

The data illustrate powerfully how the CCPE project has stimulated change in respect of both professional knowledge and understanding and to the social practices that constitute schooling in the participating schools. We conclude this paper with some brief reflections on how the project has enhanced the agency of teachers participating in the process. An ecological view of teacher agency (Priestley et al. 2015) suggests that agency is something that is achieved, rather than an innate capacity or quality of the individual. Agency emerges, unique in every situation, is shaped by influences from the past and present, and can be more or less oriented to the future. In terms of curriculum development, agency is achieved to a high degree when teachers with high levels of skill and knowledge, and particular orientations to professional practice (the iterational dimension of agency - formed by past experience) are able to form expansive aspirations about future directions in curriculum-making (the projective dimension of agency). In turn, agency is always acted out in the present, afforded by the availability of resources and limited by practical constraints, and shaped by judgement, for example evaluation of risk (the practical evaluative dimension of agency). (For an extended discussion of this theorisation of agency, see: Emirbayer and Mische 1998.)

As we noted in the introduction to this chapter, current policy, in its valorisation of the central role of the teacher, tends to over-emphasise the importance of raising individual capacity, while neglecting the cultural and structural dimensions of schooling that powerfully shape agency. CCPE potentially addresses all three dimensions. Our data suggest that the participating teachers have acquired an enhanced understanding of both concepts and processes involved in school-based curriculum development, so as a form of professional learning it clearly raises individual and collective capacity. Structurally, CCPE offers access to resources cognitive and relational, which have opened up new possibilities and new practices. On a cultural level, CCPE has clearly, in the case of the participating schools, stimulated changes, as evidenced by a shift towards emphasising children's voice, and changes in power dynamics and leadership practices, which afford 
permissions to teachers to engage in new forms of curriculum development. We suggest that such changes to the individual, structural and cultural dimensions of teachers' work, have enhanced their agency as they grapple with the complexities of developing a new curriculum: through engendering an ability to envisage a wider repertoire of pedagogical possibilities and practices in their day-to-day practice; through offering additional resources to support their professional practice; and through stimulating change to the cultures that frame their work.

\section{Acknowledgements}

We wish to acknowledge the enthusiastic participation of around 75 teachers and senior managers over the three years of the project. We also wish to offer our thanks and appreciation to East Lothian Council, particularly Alison Wishart for her support in making this programme happen. We would also like to thank Dr Cate Watson for her constructive comments on an earlier draft of this paper.

\section{References}

Biesta, G.J.J. (2004). Education, accountability and the ethical demand. Can the democratic potential of accountability be regained? Educational Theory, 54, 233-250.

Bowe, R., Ball, S. with Gold, A. (1992). Reforming Education and Changing Schools: Case Studies in Policy Sociology. London, Routledge.

Boyd, B. \& Norris, F. (2006). From development to improvement - a step too far? The evolving contribution of Quality Improvement Officers to the school improvement agenda in Scottish local authorities. Scottish Educational Review, 38, 213-224.

Butler, D., Schnellert, L. and MacNeil, K. (2015). Collaborative inquiry and distributed agency in educational change: a case study of a multi-level community of inquiry. Journal of Educational Change, 16, 1-26.

Coburn, C.E. \& Russell, J.L. (2008). District policy and teachers' social networks, Educational Evaluation and Policy Analysis, 30, $203-235$.

Coburn, C.E., Russell, J.L., Kaufman, J. and Stein, M.K. (2012). Supporting sustainability: teachers' advice networks and ambitious instructional reform. American Journal of Education, 119, 7-39.

Cochran-Smith, M. and Lytle, S. (2009) Inquiry as Stance Practitioner Research for the Next Generation. New York: Teachers College Press.

Coghlan, D. and Brannick, T. (2014). Doing Action Research in your own organisation (4th Ed.). London: Sage.

Corbin, J. and Holt, N.J. (2005) Grounded Theory. In B. Somekh and C. Lewin (eds.), Research Methods in the Social Sciences (pp. 113-120). London: Sage.

Cuban, L. (1998). How schools change reforms: redefining reform success and failure. Teachers College Record, 99, 453-477.

DeLuca, C., Shulha, J., Luhanga, U., Shulha, L.M., Christou, T.M. and Klinger, D.A. (2015). Collaborative inquiry as a professional learning structure for educators: a scoping review. Professional Development in Education, 41, 640-670.

Donaldson, G. (2010). Teaching Scotland's Future: Report of a Review of Teacher Education in Scotland. Edinburgh: Scottish Government.

Drew, V. (2013). Perceptions and possibilities: a school community's imaginings for a future 'curriculum for excellence'. Thesis submitted for the degree of Doctor of Education, School of Education, University of Stirling. Available: http://dspace.stir.ac.uk/bitstream/1893/13190/3/VDrew\%202013\%20Thesis\%202.pdf Accessed 12.08.2015.

Drew, V., Fox, A., and McBride, M. (2008). Collaborating to Improve Learning and Teaching. In J. Reeves and A. Fox (eds.), Practice-Based Learning: developing excellence in teaching (pp. 52-66). Edinburgh: Dunedin Academic Press. 
Drew, V., Priestley, M. \& Michael, M.K. (2016, in press). Curriculum Development Through Critical Collaborative Professional Enquiry. Journal of Professional Capital and Community, 1 (1), 92-106.

Education Scotland (2013). Transforming lives through learning Corporate Plan 2013-2016. Available:

http://www.educationscotland.gov.uk/Images/ESCorporatePlan tcm4-816614.pdf Accessed: 04.09.2015

Emirbayer, M. and Mische, A. (1998). 'What is agency?' The American Journal of Sociology, 103, 962-1023.

Fox, A. (2009). Leading Collaborative Professional Enquiry: Implications for Teachers, Chartered Teachers and their Managers, Thesis submitted for the degree of Doctor of Education, The Stirling Institute of Education University of Stirling. Available: http://dspace.stir.ac.uk/bitstream/1893/1756/1/Thesis\%20A.M.Fox.pdf. Accessed 12.08.2015.

General Teaching Council for Scotland (2012). The GTCS Professional Standards. Available: http://www.gtcs.org.uk/standards/standards.aspx. Accessed 04.09.2015.

Giacquinta, J.B. (1998). Seduced and Abandoned: some lasting conclusions about planned change from the Cambire School Study. In A. Hargreaves, A. Lieberman, M. Fullan and D. Hopkins (Eds.), The International Handbook of Educational Change, Part One (pp. 163-180). London: Kluwer Academic Publishers.

Griffiths, M. (2009) Action research for/as/mindful of Social Justice, in B. Somekh and S.E. Noffke (Eds.) The Sage Handbook of Educational Action Research ( $1^{\text {st }}$ ed.) (pp.85-98). London: Sage

I'Anson, J., Reeves, J. and Whewell, C. (2008) Developing excellence in teaching: redefining professional enquiry. In J. Reeves and A. Fox (eds.), Practice-Based Learning: developing excellence in teaching (pp. 67-76). Edinburgh: Dunedin Academic Press.

Jeffrey, B. and Troman, G. (eds.) (2013). Performativity Across UK Education: Ethnographic Cases of its Effects, Agency and Reconstructions (pp. 87-108). Painswick: E and E Publishing.

Jones, M., and Stanley, G. (2010). Collaborative action research: a democratic undertaking or a web of collusion and compliance? International Journal of Research and Method in Education, 33, 151-163.

Kemmis, S. (2006). Participatory action research and the public sphere, Educational Action Research, 14, 459-476.

Kemmis, S. (2009) Action Research as Practice-based Practice, Educational Action Research, 17, 463-474.

Klein, S.R. (2012). Action Research: Before You Dive In, Read This! In S.R. Klein (ed.), Action Research Methods: Plain and Simple (pp. 1-20). London: Palgrave Macmillan.

Koshy, V. (2010). Action research for improving educational practice: A step-by-step guide. $2^{\text {nd }}$ ed., London: Sage.

Kuiper, W., and Berkvens, J. (eds.) (2013). Balancing Curriculum Regulation and Freedom Across Europe. CIDREE Yearbook 2013. Enschede, the Netherlands: SLO.

Leat, D. (2014). Curriculum regulation in England: giving with one hand and taking away with the other. European Journal of Curriculum Studies, 1, 69-74.

Meirink, J., Imants, J., Meijer, P. and Verloop, N. (2010). Teacher learning and collaboration in innovative teams, Cambridge Journal of Education, 40, 161-181.

McAteer, M. (2013). Action Research in Education: Getting to Grips with Perspectives and Models. London: Sage.

McNiff, J. and Whitehead, J. (2010) . You and Your Action Research Project (3 $3^{\text {rd }}$ ed.). London, Routledge.

McNiff, J. and Whitehead, J. (2011) All you need to know about action research ( $3^{\text {rd }}$ Ed.) London, Sage

McNiff, J. (2013). Action research principles and practices ( $3^{\text {rd }}$ Ed.) London, Routledge.

OECD (2005). Teachers Matter: Attracting, Developing and Retaining Effective Teachers. Paris: OECD.

Priestley, M. and Biesta. G.J.J. (Eds.) (2013), Reinventing the Curriculum: New Trends in Curriculum Policy and Practice, London, Bloomsbury Academic.

Priestley, M., Biesta, G.J.J. and Robinson, S. (2015), Teacher Agency: An Ecological Approach, London, Bloomsbury Academic.

Priestley, M. and Minty, S. (2013), "Curriculum for Excellence: 'A brilliant idea, but.."”, Scottish Educational Review, Vol. 45,1, pp.39-52.

Reeves, J. and Drew, V. (2012), "Relays and relations: tracking a policy initiative for improving teacher professionalism", Journal of Education Policy, Vol.27, 6, pp.711-730.

Reeves, J. and Drew, V. (2013), "A Productive Relationship? Testing the Connections between Professional Learning and Practitioner Research", Scottish Educational Review, Vol.45, 2, pp.36-49.

Reeves, J. and Fox, A. (eds.) (2008). Practice-Based Learning: developing excellence in teaching. Edinburgh: Dunedin Academic Press.

Scottish Executive (2006). A Curriculum for Excellence: Progress and proposals. Edinburgh: Scottish Executive.

Somekh, B. and Zeichner, K. (2009). Action research for educational reform: remodelling action research theories and practices in local contexts. Educational Action Research, 17, 5-21. 
Drew, V., Priestley, M. \& Michael, M.K. (2016, in press). Curriculum Development Through Critical Collaborative Professional Enquiry. Journal of Professional Capital and Community, 1 (1), 92-106.

Stoll, L., Bolam, R., McMahon, A., Wallace, M. \& Thomas, S. (2006). Professional learning communities: a review of the literature. Journal of Educational Change, 7, 221-258.

Supovitz, J.A. and Weinbaum, E.H. (2008). Reform Implementation Revisited. In J.A. Supovitz and E.H. Weinbaum (eds.), The Implementation gap: understanding reform in high schools (pp. 1-21) New York: Teachers College Press.

Vescio, V., Ross, D. \& Adams, A. (2008). A review of research on the impact of professional learning communities on teaching practice and student learning. Teaching and Teacher Education, 24, 80-91.

Wilkinson, J. and Kemmis, S. (2015) "Practice Theory: Viewing leadership as leading", Educational Philosophy and Theory. Vol. 47.4, pp. 342-358

Young, M.D.F. (1998). The curriculum of the future: from the "new sociology of education" to a critical theory of learning. London, Routledge.

Zeichner, K.M. (2002). Teacher research as professional development for P-12 educators in the USA [1]. Educational Action Research, 11, 301-326.

\footnotetext{
${ }^{1}$ Please note that we employ the spelling most commonly used in Scotland ('enquiry') throughout this paper, except where quoting directly from other authors using alternative spelling 'inquiry'.

${ }^{2}$ In the case of CfE, these are set out in the Four Capacities. These are the top level purposes of the curriculum. They have become a sort of mantra, widely visible as slogans on posters in schools, but often stripped of meaning. In fact, they form a useful starting point for curriculum planning, being broken down into a set of key competences known as attributes and capabilities, which define the skills and knowledge to be acquired by an educated person. See:

http://www.educationscotland.gov.uk/learningandteaching/thecurriculum/whatiscurriculumforexcellence/thepurposeofthecurr iculum/index.asp

${ }^{3}$ The initialisation Es and Os is commonly used to refer to the Experiences and Outcomes - hundreds of learning outcomes set out in hierarchical levels - that comprise the front end of Curriculum for Excellence most commonly used in schools to plan activities. See:

http://www.educationscotland.gov.uk/learningandteaching/thecurriculum/howisthecurriculumorganised/experiencesandoutco mes/
} 